\title{
Consecutive Removal of Hazardous Dyes from Aqueous Solutions by Composite hydrogels Based on Rice Straw
}

\author{
Samia E. Abdel-Aal ${ }^{a}$, Ghada A. Mahmoud ${ }^{a,{ }^{*}}$, A.A. Elbayaa ${ }^{b}$, Nagwa A. Badway ${ }^{b}$ and \\ Doaa F. Ahmed ${ }^{b}$ \\ ${ }^{a}$ National Center for Radiation Research and Technology, Atomic Energy Authority, P.O. Box 29, Nasr City, \\ Cairo, Egypt \\ ${ }^{b}$ Chemistry Department, Faculty of Science, Al-Azhar University, Nasr City, Cairo, Egypt
}

\begin{abstract}
The composite hydrogels based on rice straw (RS) and N-vinyl-2-pyrrolidone (NVP) or acrylamide (AAm) were successfully prepared by gamma irradiation. The effect of the radiation dose and the monomer content on the gel percent was studied. The composite hydrogels were confirmed by (FTIR), (TGA) and (SEM). It was found that the diffusion of water into the prepared composites was Fickian character. The removal of congo red (CR) and methyl orange (MO) dyes by (NVP/RS) and (AAm/RS) composite hydrogels were investigated as a function of the pH, contact time, initial dye concentration solution and temperature. It was achieved that the adsorption capacity of (NVP/RS) composite hydrogel towards (CR) and (MO) was higher than (AAm/RS) one. The kinetic data was tested by the pseudofirst-order and the pseudo-second-order kinetic models. The adsorption isotherm was closely fitted with the Freundlich model for adsorption of CR and MO onto (NVP/RS) and the Langmuir model for adsorption of the dyes onto (AAm/RS). A high adsorption capacity was obtained in the second adsorption cycle of $\mathrm{MO}$ onto the composite hydrogels loaded with CR. Improvement in the adsorption of MO onto (NVP/RS) and (AAm/ RS) composite hydrogels loaded with $\mathrm{Co}(\mathrm{II})$.
\end{abstract}

Keyword: Agricultural waste, Kinetics, isotherm, Radiation, secondary adsorption.

\section{INTRODUCTION}

Water is the most important natural resource in the world without it life cannot exist. Enormous amounts of dyestuff are consumed annually by various sectors of industry such as textile, rubber, paper, leather, plastics, cosmetic, and printing [1]. The discharge of dyes effluents in the environment is worrying for both toxicological and aesthetical reasons [2]. This dyebearing wastewater exhibits high colour and high chemical (COD) and biochemical oxygen demands (BOD) [3]. Various techniques for dye removing from effluents have been developed include the electrochemical treatment, non- chemical treatment, and adsorption etc [4]. Adsorption is recommended as an effective and economical method to remove dyes even at high concentrations. Adsorption is recommended as an effective and economical method to remove dyes even at high concentrations. It has some benefits of high efficiency and ease of handling. Moreover, the majority of sorbents, either synthetic or natural, is having the advantage of the reusability [5]. Therefore, the interest focused on finding an effective sorbent having high adsorption capacity, fast adsorption/ desorption rate, and regeneration strongly increased last decade [6]. Researchers have

*Address correspondence to this author at the National Center for Radiation Research and Technology, Atomic Energy Authority, P.O. Box 29, Nasr City, Cairo, Egypt; Tel: +2-01065495895; Fax: +2-022 2749298;

E-mail: ghadancrrt@yahoo.com contributed largely to find low-cost adsorbents with greater adsorption capacities that can remove dyes from the effluent such as agricultural waste because of their unique advantages; nontoxic, biocompatible, biodegradable, inexpensive, and abundant $[7,8]$. Rice straw is one of the most abundant agricultural wastes rich with active groups. It mainly consists of cellulose, pectin, hemicelluloses lignin, chlorophyll, pigment and other low molecular weight hydrocarbons [9]. On the other hand, open field burning of rice straw frequently causes serious air pollution. So, many studies have been investigated the rice straw for removal of dyes from aqueous solutions [10]. However, most of raw biosorbents have a low sorption capacity and mechanical properties. Sometimes they do not contain suitable functional group for effective adsorption. So, it can be overcome by copolymerization with a synthetic polymer. Hydrogels are three-dimensional polymeric networks formed by chemical or physical crosslinking. These are capable of imbibing large amounts of water and it can become stimuli responsive when contain some specific functional groups and this property brings the volume phase transitions and makes these materials useful for advanced technologies [11].

In previous study orange peel/ N-vinyl-2-pyrrolidone has been investigated for removal of dyes [12]. In this study, composite hydrogels based on rice straw (RS) waste were copolymerized with $\mathrm{N}$-vinyl-2-pyrrolidone (NVP) and acrylamide (AAm) monomers as synthetic monomers by gamma irradiation technique. These 
composite hydrogels were used as adsorbents for the removal of congo red (CR) and methyl orange (MO) dyes from aqueous solutions. The factors influencing the adsorption properties were determined. The dye loaded hydrogels were reused to removal dyes as a second adsorption cycle.

\section{MATERIALS AND METHODS}

\section{Materials}

Rice straw was obtained from rice fields in Egypt, Acrylamide (AAm) was purchased from Winlab (99\%) (UK) and N-Vinyl-2-Pyrrolidone (NVP) of purity $99 \%$ (Merck, Germany). For pH adjustment throughout the experiment, $(0.1 \mathrm{M}) \mathrm{HCl}$ and/or $\mathrm{NaOH}$ solutions were used as necessary. Methyl orange (MO) (Figure 1) of molecular weight 327.34 a.m.u was purchased from Sigma-Aldrich, Congo red dye (CR) has a molecular weight of 696.66 a.m.u was obtained from Sigma Aldrich with $99.99 \%$ purity. All chemicals and reagents are used as received without any further purification.

\section{Rice Straw Treatment}

Rice straws were washed thoroughly with distilled water to remove adhering dirt and were left to dry in sunlight until all moisture evaporated, then crushed. The ground powder was treated with $4 \% \mathrm{NaOH}$. The rice straw was filtered and washed with distilled water to remove the free $\mathrm{NaOH}$ then dried in air.

\section{Radiation Preparation of Rice Straw Composite Hydrogels}

(NVP/RS)and (AAm/RS) composite hydrogels were prepared by adding $0.1 \mathrm{~g}$ of the treated rice straw to different content of NVP or AAm monomer solution, stirred for $5 \mathrm{~h}$. The viscous solutions were transferred into vials to be irradiated with the $\mathrm{Co}^{60}$ gamma source at different radiation doses $(10-50 \mathrm{kGy})$ at a dose rate of $1.46 \mathrm{kGy} / \mathrm{h}$. It is installed at the National Center for Radiation Research and Technology, Atomic Energy Authority, Egypt. After copolymerization, the vials were broken; the formed polymeric cylinders were removed and cut into discs of $2 \mathrm{~mm}$ thickness and $5 \mathrm{~mm}$ diameter. The composite gels were washed with distilled water to remove the unreacted component, then air dried at room temperature.

To determine the insoluble parts, the samples were air-dried to a constant weight. The dried samples were soaked in distilled water for $24 \mathrm{~h}$ at $70{ }^{\circ} \mathrm{C}$ then; taken out and washed with hot water to remove the soluble part and dried to a constant weight. The gel content was calculated gravimetrically with the following formula:

Gel content $(\%)=\frac{\mathrm{W}_{\mathrm{d}}}{\mathrm{W}_{0}} \times 100$

Where $W_{d}$ and $W_{0}$ are the dried sample weights after and before extraction, respectively.

\section{Swelling Measurements}

The clean, dried, weighed composite hydrogel was soaked in distilled water at room temperature for different interval time durations. The sample was removed and the excess water on the surface was removed by blotting quickly with filter paper and reweighed. The swelling percent was calculated as follows:

Swelling $(\%)=\frac{M_{s}-M_{d}}{M_{d}} \times 100$

Where $M_{d}$ and $M_{s}$ are the masses of dry and swelled sample, respectively.

\section{Characterization of the Composite Hydrogels}

The synthesized composites were characterized by FTIR recorded on Nicolet IS-10FTIR, within the range of $400-4000 \mathrm{~cm}^{-1}$ using $\mathrm{KBr}$ pellets.

To study the morphology of the composites, the scanning electron micrographs were recorded by JEOL-JSM- 5400 scanning electron microscope, Tokyo, Japan. Before the examination, the materials were dried, coated with sputtered gold, observed and photographed.

The thermal properties of the hydrogels were investigated by Shimadzu TGA system of type TGA-50, Japan, under the nitrogen atmosphere $(20 \mathrm{ml} / \mathrm{min})$. The temperature ranged from ambient to $600{ }^{\circ} \mathrm{C}$ at a heating rate of $10{ }^{\circ} \mathrm{C} / \mathrm{min}$. The primary TGA thermograms were used to determine the rate of thermal decomposition reaction.

\section{Adsorption Studies}

Batch adsorption experiments were carried out at different temperatures ranged between 30 and $60^{\circ} \mathrm{C}$. $20 \mathrm{ml}$ of known initial concentration of the dye solution at adjacent $\mathrm{pH}$ was shaken at the certain agitation speed 250rpm with a known dose of the dried hydrogel 
at appropriate time intervals. The percentage removal of dye was calculated using the following equation:

$\operatorname{Removal}(\%)=\frac{\left(\mathrm{C}_{0}-\mathrm{C}_{\mathrm{t}}\right)}{\mathrm{C}_{0}} \times 100$

where, $\mathrm{C}_{0}$ and $\mathrm{C}_{\mathrm{t}}$ (both in $\mathrm{mg} / \mathrm{L}$ ) are the initial dye concentration and the dye concentration at time $t$, respectively.

The adsorption capacity $\mathrm{q}_{\mathrm{t}}(\mathrm{mg} / \mathrm{g})$ was calculated using the following equation: $q e=\frac{\left(C_{i}-C_{e}\right)}{W} \times V$

Where $\mathrm{V}$ is the solution volume $(\mathrm{L}), \mathrm{W}$ is the mass of sample $(\mathrm{g})$, and $\mathrm{C}_{\mathrm{i}}$ and $\mathrm{C}_{\mathrm{e}}$ are the initial and equilibrium dye concentrations ( $\mathrm{mg} / \mathrm{L}$ of dye) respectively. The dye concentration was determined using UVIVIS spectrometer model UV-Analytic Jena made by German was used at $\lambda_{\max }$ of $500 \mathrm{~nm}$ for $C R$ and $464 \mathrm{~nm}$ for $\mathrm{MO}$ with a quartz cell of $1.0 \mathrm{~cm}$ optical length.

\section{Initiation}

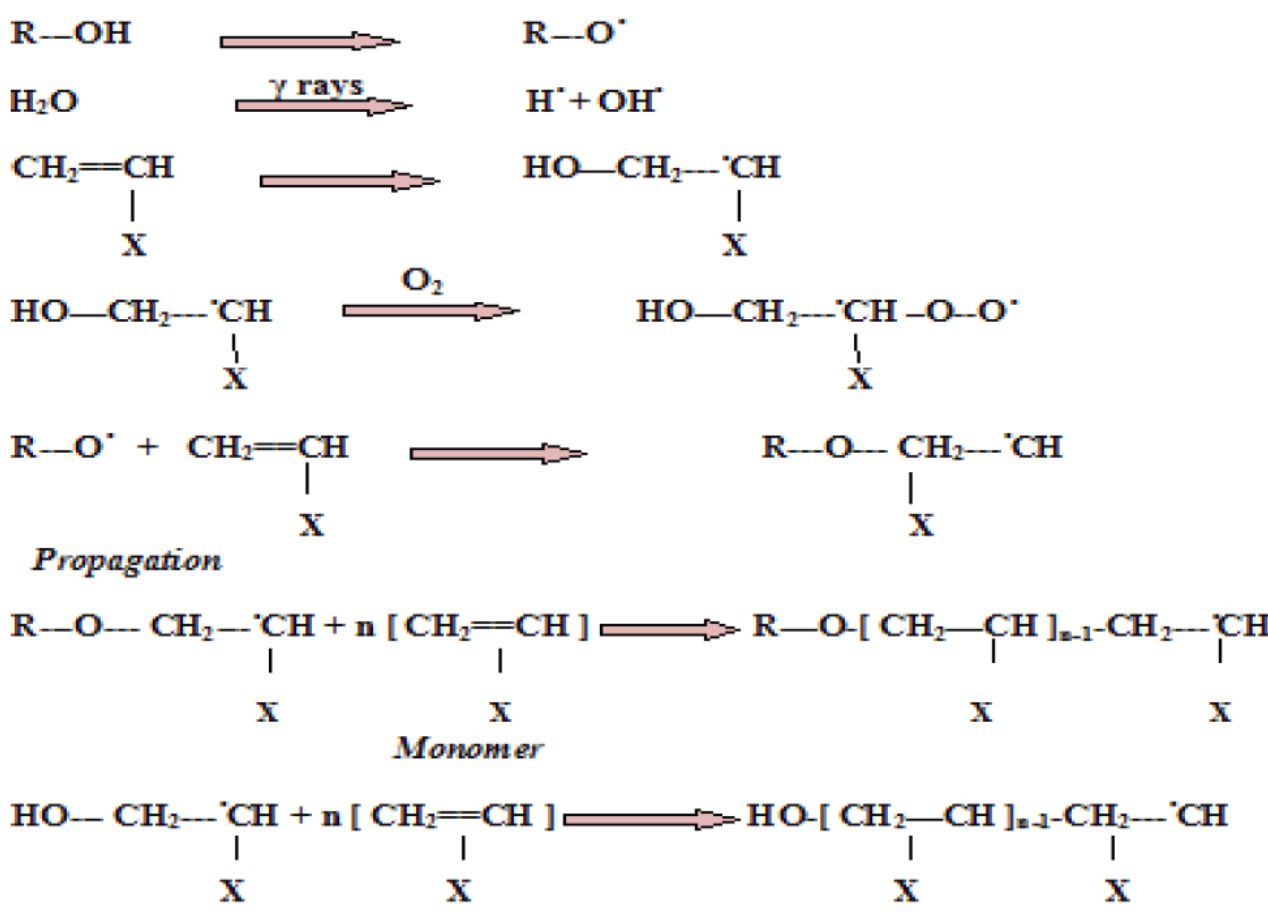

Monomer

Homopolymer
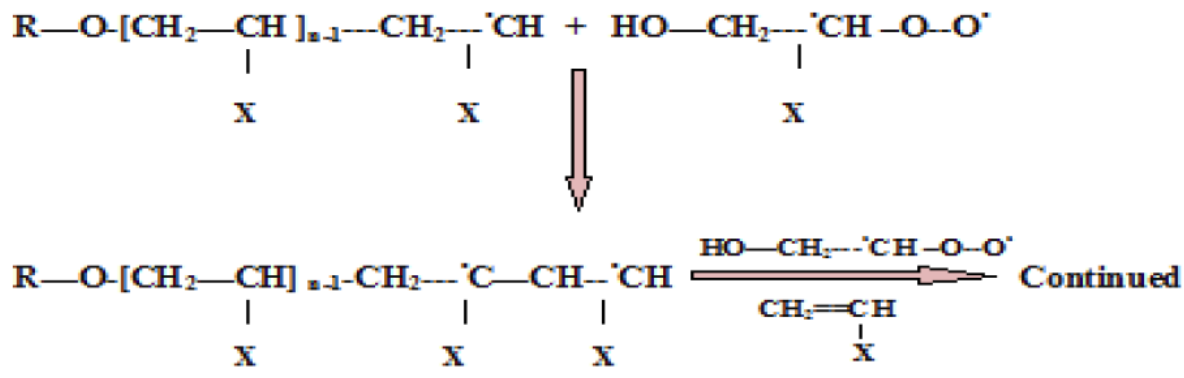

\section{Macro radicals}

Where $X$ is

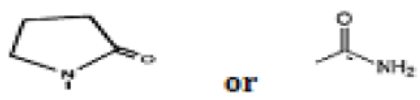

Scheme 1: 


\section{RESULTS AND DISCUSSION}

Radiation formation of composite hydrogels in aqueous solution proceeds by radical mechanism. Possible mechanism of radiation- induced crosslinking polymerization is shown in Scheme 1. Polymerization by this method involves the irradiation of aqueous polymer/monomer solutions result in the formation of the radicals on the polymer chains and monomer. Radiolysis of water involves the formation of hydroxyl radicals, which attack the polymer chains thus leading to the macroradicals formation. Both polymerization and crosslinking processes are played by indirect effect, i.e. these processes are initiated by intermediate products of radiolysis of water [13]. On the same analogy, the radicals are formed on RS, NVP or AAm during the initiation step. Further propagation of macroradicals leads to a formation of the product. Recombination of the macroradicals on different chains results in the formation of covalent bonds, and finally a crosslinked structure i.e (RS/NVP) or (RS/AAm).

\section{Effect of Gamma Radiation Dose on the Gel Percent}

Figure 1 shows the gel percent of (NVP/RS) and (AAm/RS) composite hydrogels as a function of radiation dose. The Figure presented that the gel percent was increased with the increase in radiation dose. When a solution of rice straw and NVP or AAm monomers are irradiated with $y$-rays, free radicals are generated on polymer and monomers. Random reactions of these radicals cause polymerization and formation of a network. The increase in the total radiation dose enhances the free radicals formation and can easily form more crosslinks between cellulose chains in rice straw and monomer (AAm, NVP) to create a three-dimensional network. By comparing the gelation of (NVP/RS) and (AAm/RS) it can be noted that, the conversion rate of (AAm/RS) to composite hydrogels is higher than (NVP/RS), although, the maximum gel percent of (AAm/RS) is as the same as of (NVP/RS) at radiation dose $50 \mathrm{kGy}$. This means the ability of conversion of AAm monomer to gel is higher than that of NVP. This is understandable since the Gvalue of $A A m$ monomer is much higher than that of NVP monomer. Also, it must be focused here on that, there is no degradation in RS upto the investigated radiation dose (50 kGy).

\section{Effect of Monomer Content on the Gel Percent}

The properties of hydrogels are governed by the monomer content in the reaction mixtures. The capacity to form a gel and to provide structural matrix under practical conditions are important in the preparation of hydrogels. Figure 2 represents the effect of NVP and AAm content on the gel percent of (NVP/RS) and (AAm/RS) composite hydrogel, respectively, at irradiation dose $30 \mathrm{kGy}$. It can be noted that the increase in the gel percent as a result of the increase in the monomer concentration referred to the

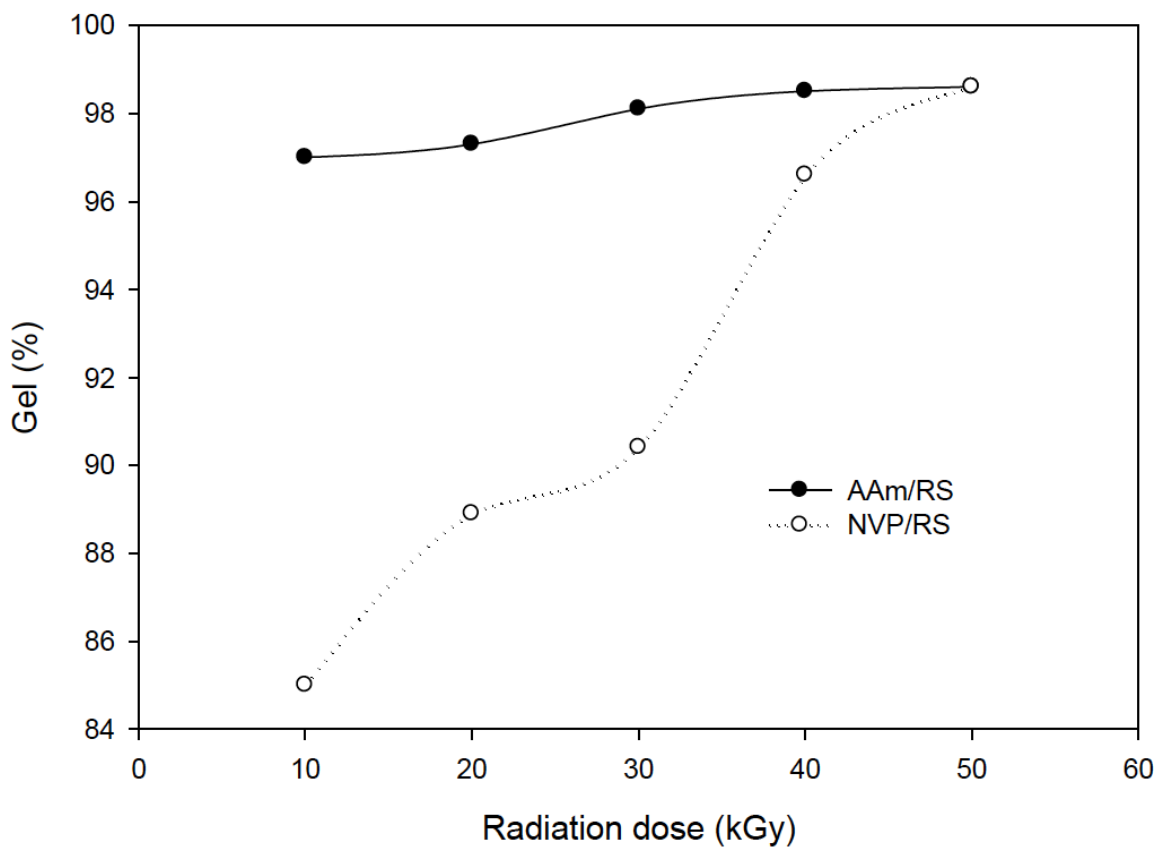

Figure 1: Effect of total radiation dose on the gel percent of (NVP/RS) and (AAm/RS) composite hydrogel at monomer concentration $20 \mathrm{wt} \%$. 


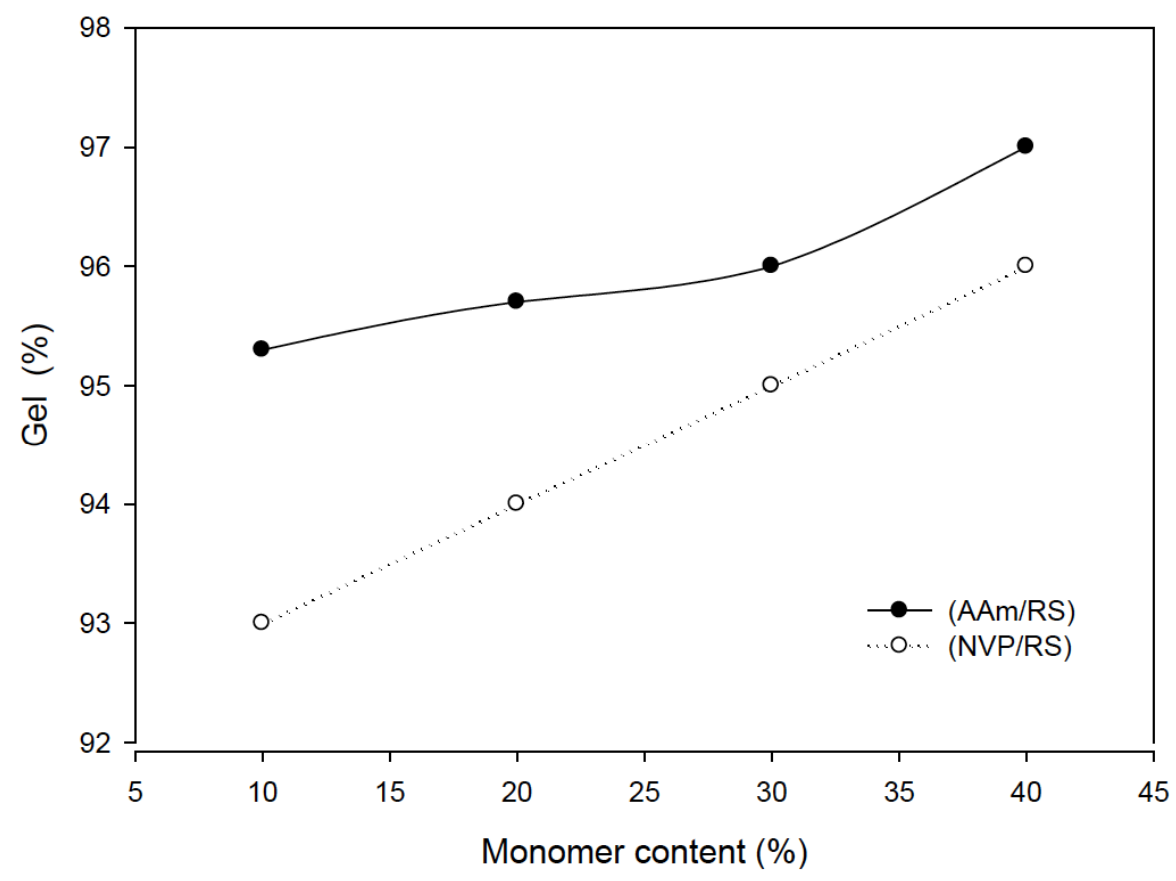

Figure 2: Effect of monomer content on the gel percent of (NVP/RS) and (AAm/RS) composite hydrogel at radiation dose of $30 \mathrm{kGy}$.

increase in the number of the radicals on the reactive vinyl groups [14]. Also, AAm monomer favors the formation of hydrogel even at low monomer concentration thus the (AAm/RS) composite hydrogel has higher gel content than (NVP/RS) composite hydrogel at the same radiation dose and monomer content.

\section{FT-IR Analysis}

Figure 3 shows the FTIR spectra of (NVP/RS) and (AAm/RS) composite hydrogels where the percent of transmittance is plotted as a function of the wavenumber $\left(\mathrm{cm}^{-1}\right)$. For NVP/RS composite hydrogel the bands appeared at 3428.85 and $2947.83 \mathrm{~cm}^{-1}$ ascribed to the stretching vibration of $-\mathrm{OH}$ groups and the $\mathrm{C}-\mathrm{H}$ stretching, respectively, and confirmed the presence of free $-\mathrm{OH}$ groups on the adsorbent surface as components of the RS. The band at $1661.51 \mathrm{~cm}^{-1}$ due to $\mathrm{C}=\mathrm{O}$ stretching vibration of cyclic amide of (NVP). The band at $1495 \mathrm{~cm}^{-1}$ indicated the asymmetric $\mathrm{COO}-$ and $\mathrm{C}-\mathrm{C}$ stretching of the aromatic compound of lignin. The band at $1463 \mathrm{~cm}^{-1}$ indicated the $-\mathrm{CH}_{3}$ of lignin. The $\mathrm{C}-\mathrm{N}$ bending and stretching of (NVP) appeared at 1425 and $1289 \mathrm{~cm}^{-1}$, respectively. The stretching vibration of $-\mathrm{SO}_{3}$ of hemicelluloses appeared at $1373 \mathrm{~cm}-1$. The bands in the region of $1200-1025 \mathrm{~cm}^{-1}$ due to $\mathrm{C}-\mathrm{O}$ and $\mathrm{C}-\mathrm{O}-\mathrm{C}$ stretching vibrations respectively, which are characteristics of the natural polysaccharides functional group. For (RS/AAm) composite the band at $3420.85 \mathrm{~cm}^{-1}$ ascribed to the stretching vibration of $-\mathrm{OH}$ groups. The bands at 2937 and $2868 \mathrm{~cm}^{-1}$ correspond to the asymmetric and symmetric $\mathrm{C}-\mathrm{H}$ stretching vibration of $\mathrm{CH}_{2}$ groups in the cellulose, respectively. the characteristic absorption peaks of polyacrylamide; $1666 \mathrm{~cm}^{-1}, 1612 \mathrm{~cm}^{-1}$, and $1303-1338 \mathrm{~cm}^{-1}$ indicate the $\mathrm{C}=\mathrm{O}, \mathrm{N}-\mathrm{H}$ bending and $\mathrm{C}-\mathrm{N}$ stretching, respectively, which are the characteristics of the amide $\left(-\mathrm{CONH}_{2}\right)$ group [15]. The band at $1416 \mathrm{~cm}^{-1}$ indicated the $-\mathrm{CH}_{3}$ of lignin. The stretching vibration of $-\mathrm{SO}_{3}$ of hemicelluloses appeared at $1320 \mathrm{~cm}^{-1}$.

\section{The Swelling Behavior}

Figure 4 shows effect of time on the swelling percent of (NVP/RS) and (AAm/RS) composite hydrogels at various radiation doses. It can be seen that the swelling percent is increased with the increase in the swelling time to reach a certain limiting value after $5 \mathrm{hr}$. On the other hand, the increase in the radiation dose led to a reduction in the swelling ability. This is attributed to a higher degree of crosslinking under a higher radiation dose.

Figure 5 shows effect of monomer content on the swelling percent of (NVP/RS) and (AAm/RS) composite hydrogels. It can be observed that the swelling percent decreased with increasing the monomer content in the composite. When the monomer content in the feed mixture has increased the viscosity of reaction medium also increased. A high crosslinked chain was obtained 


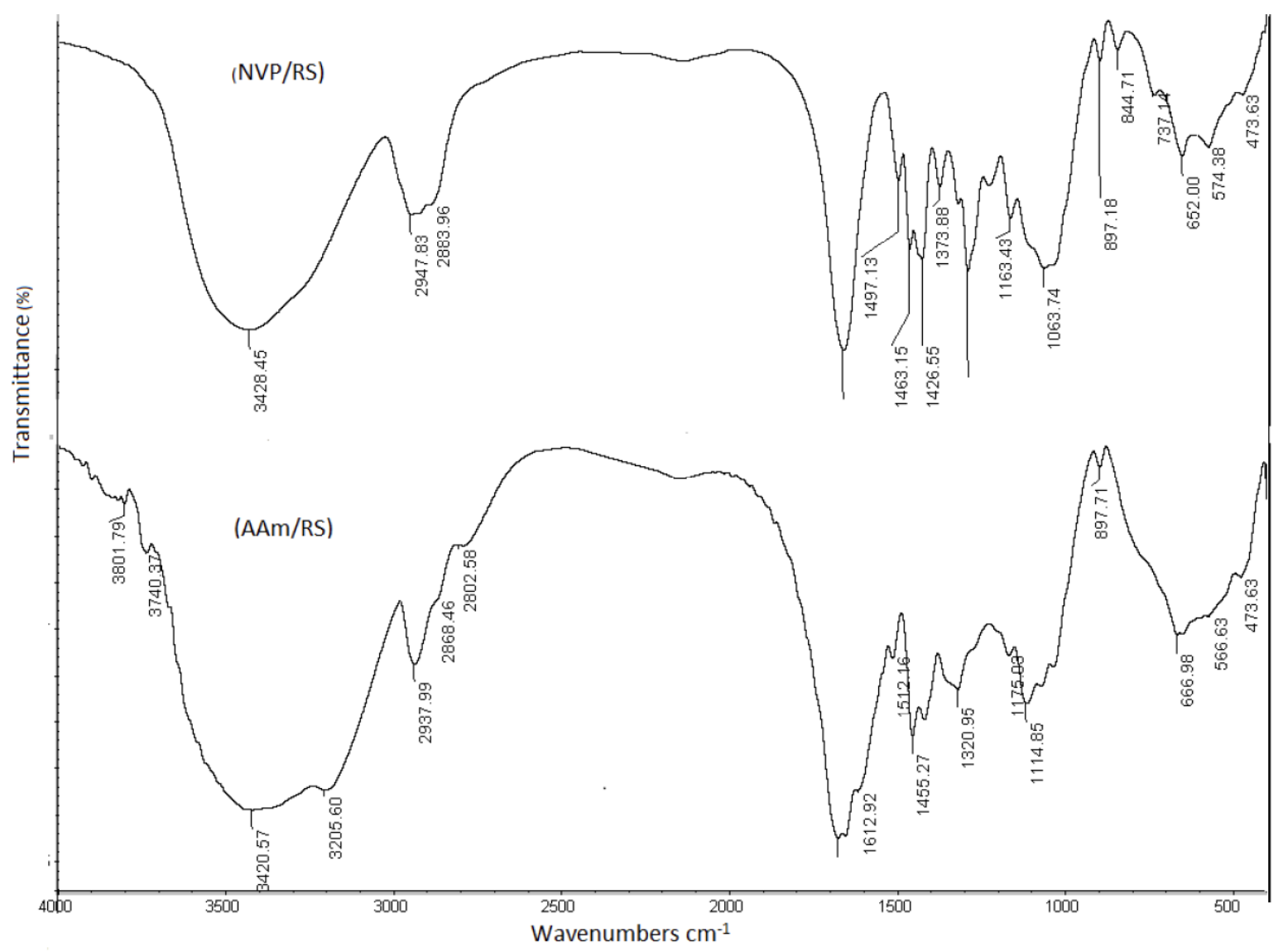

Figure 3: FTIR spectra of (NVP/RS) and (AAm/RS) composite hydrogel.
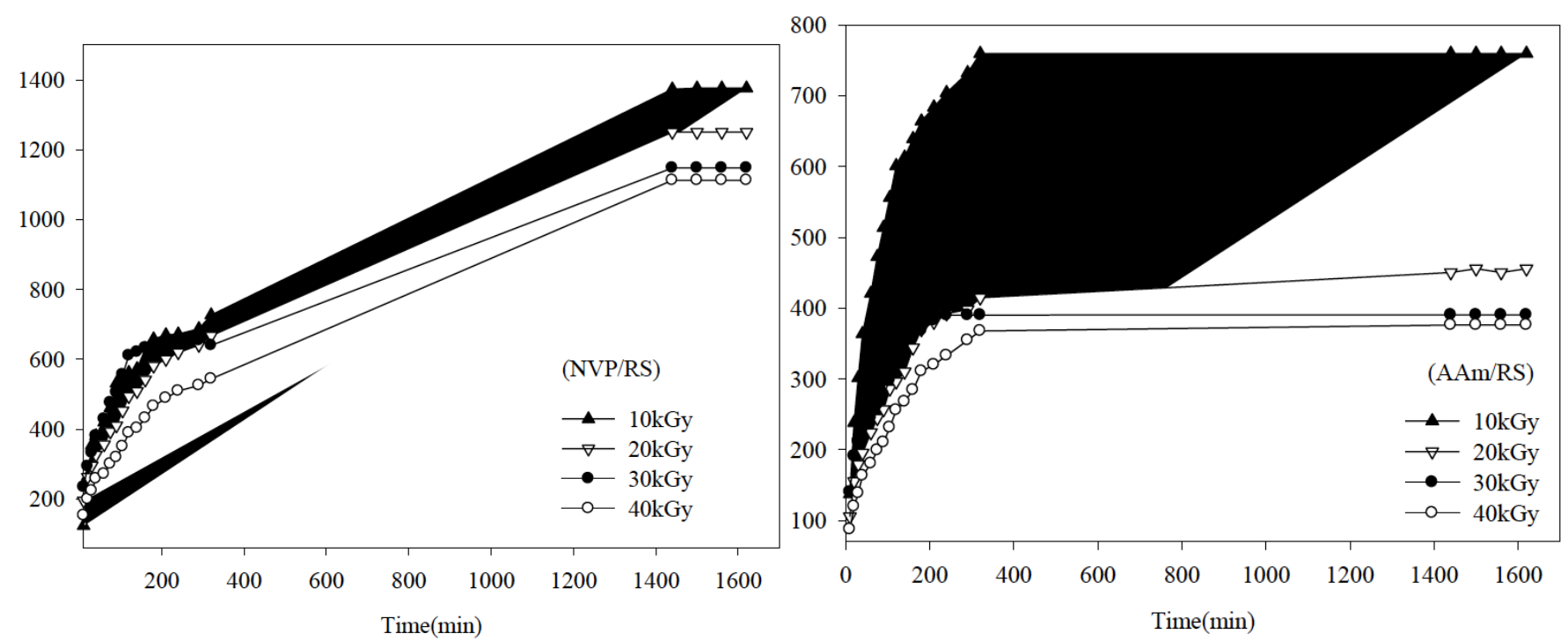

Figure 4: Effect of time on the swelling percent of (NVP/RS) and (AAm/RS) composite hydrogels of 20 wt\% monomer concentration at various radiation doses.

as well as a decrease in the swelling percent obtained [14]. In addition, the swelling percent of the hydrogel containing NVP is lower than that contains AAm which means the hydrophilicity of NVP is not as higher as that of AAm monomer.

\section{Thermogravimetric Analysis (TGA)}

Figure 6 represents the TGA and the rate of thermal decomposition (dw/dt) curves of (NVP/RS) and (AAm/RS) composite hydrogels at temperature ranged from 25 to $600^{\circ} \mathrm{C}$. For (AAm/RS) the first 


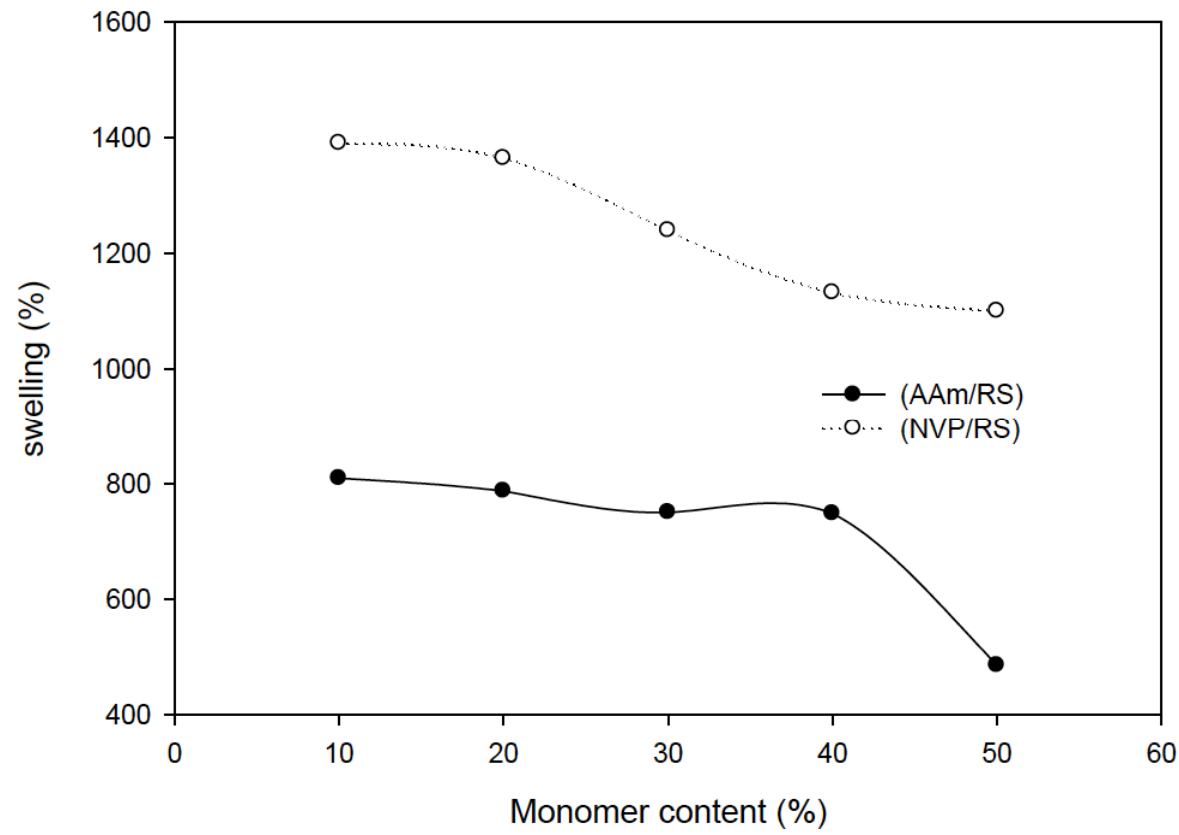

Figure 5: Effect of monomer content on the swelling percent of (NVP/RS) and (AAm/RS) composite hydrogels at radiation dose 30 kGy.

decomposition stage occurred in the range of 20$200^{\circ} \mathrm{C}$ corresponding to the evaporation of intra and intermolecular moisture. The copolymers contained hydrophilic groups which could induce the sample to combine with water molecules. The second decomposition stage occurred in the range of 200 $300{ }^{\circ} \mathrm{C}$ corresponding to the imine reaction of a small number of the amide groups and the thermal decomposition of hydrophobic side chains. The third decomposition stage occurred in the range of $300-$ $450{ }^{\circ} \mathrm{C}$ corresponding to the decomposition of the amide groups and degradation of the main polymer chains. Above $450{ }^{\circ} \mathrm{C}$ complete decomposition of the copolymer was observed. In the case of (NVP/RS) composite hydrogel, the thermogarm shows three characteristic stages of decompositions. The first decomposition stage in the temperature ranges of 29$130{ }^{\circ} \mathrm{C}$ which due to the vaporization of physically absorbed water. The second decomposition stage was between $130-400{ }^{\circ} \mathrm{C}$ due to the anhydride formation and degradation of the intermolecular side chain. The main weight loss occurred in the third decomposition stage in the range of $400-475^{\circ} \mathrm{C}$ which attributed to the decomposition of the backbone polymer.

\section{Dye Removal}

In this part (AAm/RS) and (NVP/RS) composite hydrogels are used to remove congo red (CR) and methyl orange (MO) dyes from wastewater. The major components of RS are; lignin, tannins and other phenolic compounds. Hydroxyl and carboxyl group are efficient ion exchange compounds and that active sites are the phenolic groups of those compounds. The adsorption efficiency was enhanced by copolymerization with AAm or NVP in (AAm/RS) or (NVP/RS), respectively. It was provided lots of adsorption sites for removal of dyes. It is well-known that there is strong interaction between $(-\mathrm{C}=\mathrm{O}$ and $-\mathrm{C}$ $\mathrm{N})$ adsorbed sites in NVP or $(-\mathrm{C}=\mathrm{O}$ and $-\mathrm{NH} 2)$ groups in AAm and dyes molecules $[16,17]$.

The $\mathrm{pH}$ value of the dye solution affects the chemistry of both the dye molecules and the adsorbent materials [18]. Simultaneously, the effect of $\mathrm{pH}$ on the adsorption was examined over $\mathrm{pH}$ ranges between 5.0 $-10.0 \mathrm{CR}$ and the results are presented in Figure 7. In Figure $7 \mathrm{a}$ when the $\mathrm{pH}$ is increased from 5 to 7 , the adsorption capacity of $\mathrm{CR}$ and $\mathrm{MO}$ is also increased and then decreases above $\mathrm{pH} 7$. Thus, the maximum removal of $\mathrm{CR}$ and $\mathrm{MO}$ is at $\mathrm{pH}=7$ by using both hydrogels. Therefore, further adsorption experiments were carried out at $\mathrm{pH}=7$. Similar results for $\mathrm{MO}$ adsorption on different adsorbents were reported elsewhere [19]. At elevated initial $\mathrm{pH}$ values, the decrease in uptake value could be attributed to enhance the formation of $\mathrm{OH}$ - ions that compete with the dye anionic species for the adsorption sites but at lower $\mathrm{pH}$ value, predominating adsorbed species is the molecular form of the adsorbate, while ionized form is preferentially adsorbed. It may be interpreted from present adsorption process that the surface of natural 

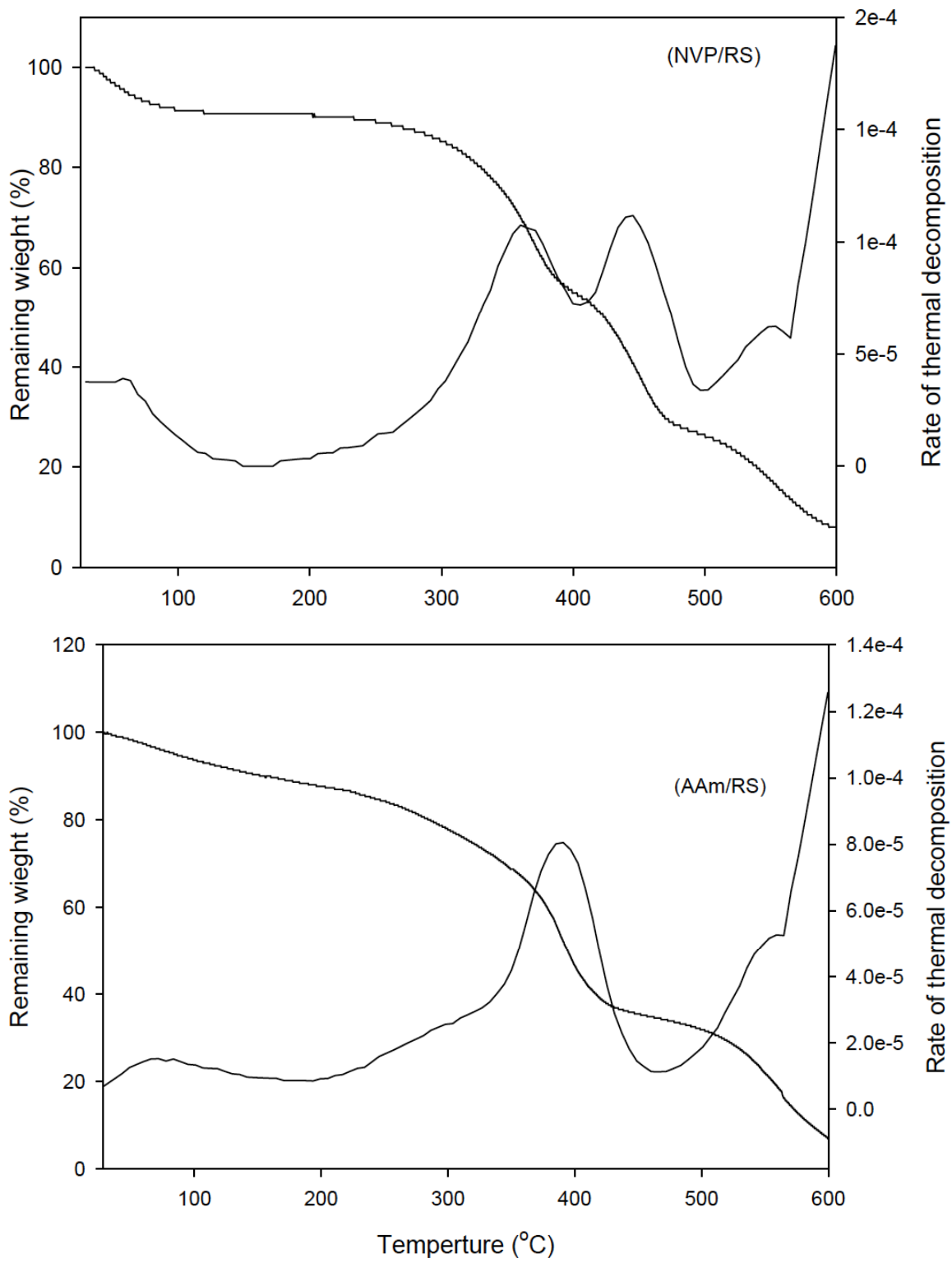

Figure 6: TGA and the rate of thermal decomposition (dw/dt) curves of (NVP/RS) and (AAm/RS) composite hydrogels

polymer had more preference for the dissociated species of the dye at neutral $\mathrm{pH}$. Rice strew is a heterogeneous polymer of cellulose, hemicellulose and lignin and thus contains various functional groups, such as carboxyl and hydroxyl, etc. The interaction of the dye molecules with these functional groups may follow extremely complicated. There is may be a weak electrostatic interaction between the dye molecules and electron deficient sites on the composite surface.

It can be also noted that the adsorption capacity of (NVP/RS) composite hydrogel towards the investigated dyes is higher than (AAm/RS) one. This observation could be explained by considering bridging mechanism [20]. In different hydrogel, the dangling of poly ( $\mathrm{N}$-vinyl2-pyrrolidone) chains has better approachability than polyacrylamide [21]. Also, it may be attributed to the increase of free volume available for diffusion and specific bonding of positively charged dye to completely ionized hydrogel. This result is supported by SEM as shown in Figure $\mathbf{8}$ the porosity of the composite hydrogel contains NVP is higher than that contains AAm.

The adsorbed amount of $\mathrm{CR}$ and $\mathrm{MO}(\mathrm{mg})$ per gram of both composite hydrogels versus contact time were investigated at initial dye concentration $10(\mathrm{mg} / \mathrm{L})$ and presented in Figure 9. It can be observed that the increase in contact time leads to increase the amount of adsorbed dye and the equilibrium is reached within 6000 and $8000 \mathrm{~min}$ for (NVP/RS) and (AAm/RS), respectively. The adsorption process proceeds in 

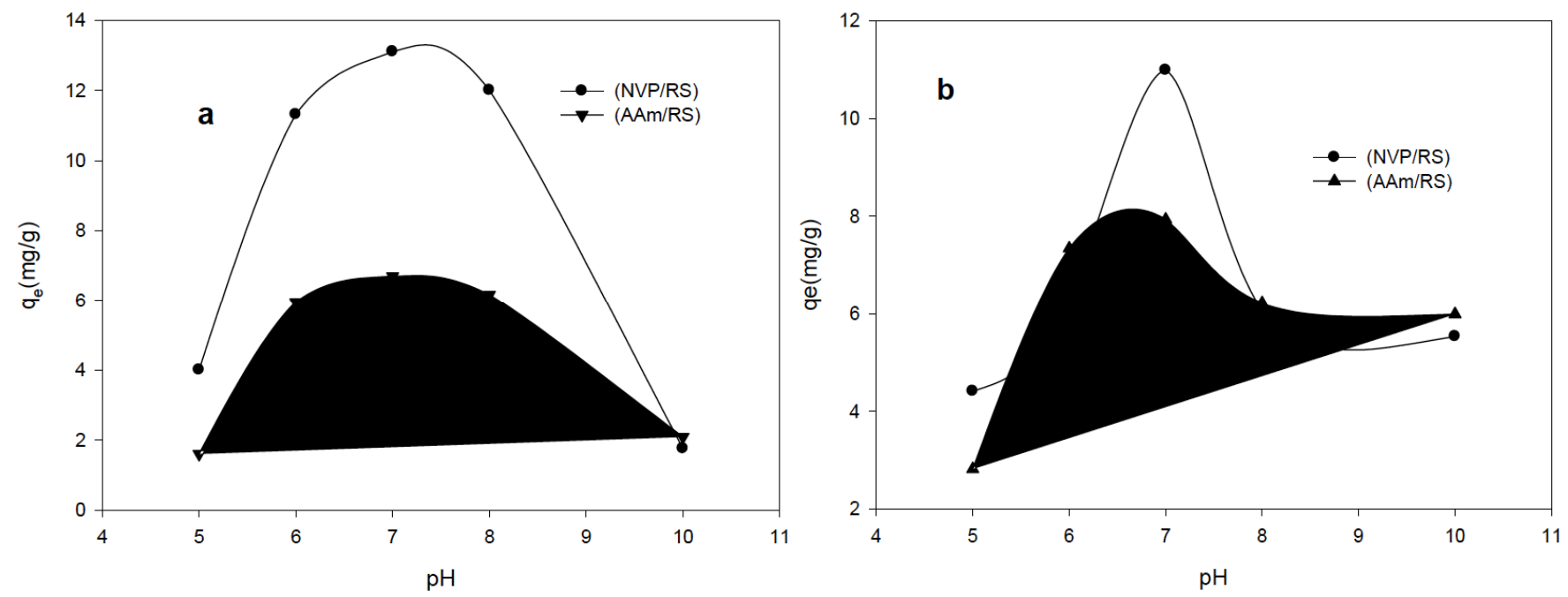

Figure 7: Effect of $\mathrm{pH}$ on the adsorption of $\mathrm{CR}(\mathbf{a})$ and $\mathrm{MO}(\mathbf{b})$ by (NVP/RS) and (AAm/RS) composite hydrogels at $25^{\circ} \mathrm{C}$ and initial dye concentration $25 \mathrm{mg} / \mathrm{L}$.
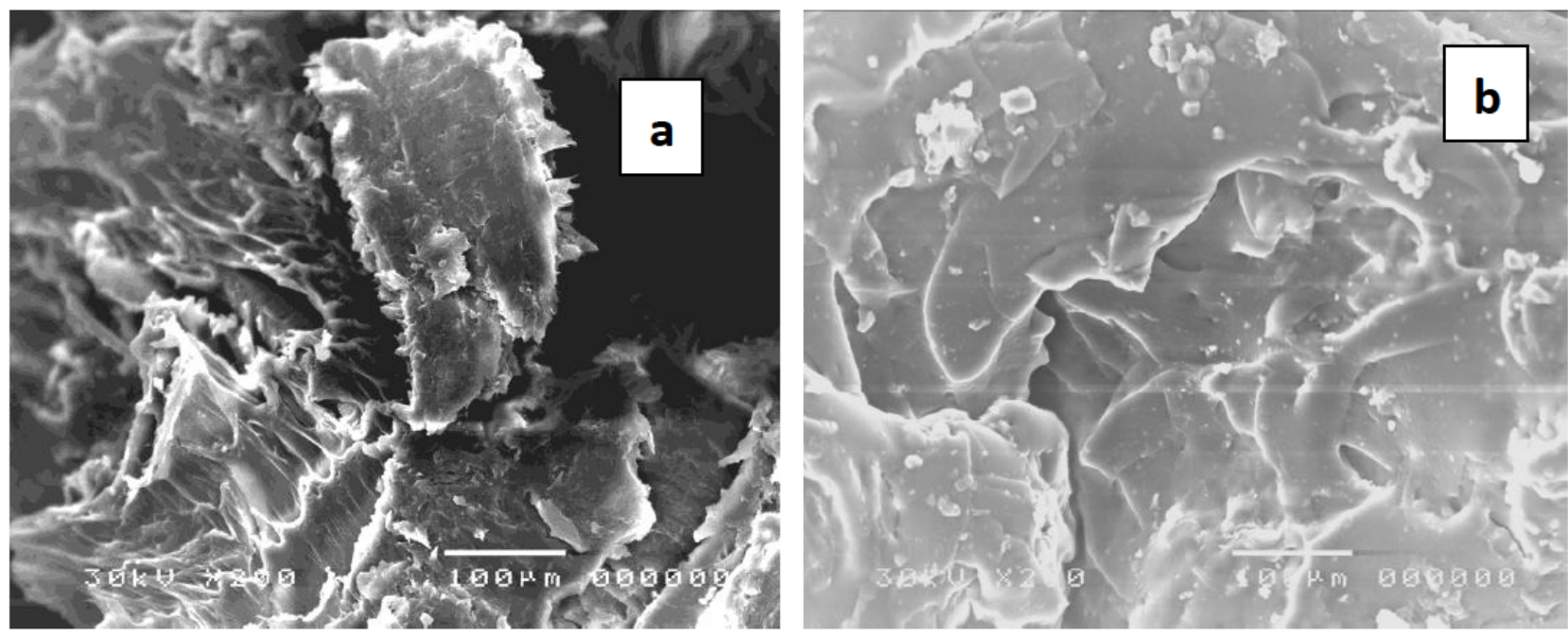

Figure 8: SEM micrographs of hydrogel surfaces of (NVP/RS) (a) and (AAm/RS) (b) composite hydrogels.

several steps involving transport of the solute from solution to the surface of the solid particles and diffusion of the solute into the interior of the pores which is usually a slow process [22]. To investigate the mechanism of adsorption, the behavior of the dye adsorption process is analyzed using the pseudo-firstorder [23] and pseudo-second-order [24] which are explained as follow:-

\section{Pseudo-first-order mode}

$\log \left(\mathrm{q}_{\mathrm{e}}-\mathrm{q}_{\mathrm{t}}\right)=\log \mathrm{q}_{\mathrm{e}}-\frac{\mathrm{k}_{1}}{2.303} \mathrm{t}$

Pseudo-second-order model

$\frac{\mathrm{t}}{\mathrm{q}_{\mathrm{t}}}=\frac{1}{\mathrm{k}_{2} \mathrm{q}_{\mathrm{e}}^{2}}+\frac{1}{\mathrm{q}_{\mathrm{e}}} \mathrm{t}$ where $\mathrm{q}_{\mathrm{e}}$ and $\mathrm{q}_{\mathrm{t}}$ are the amounts of dye adsorbed $(\mathrm{mg} / \mathrm{g})$ at equilibrium and time $\mathrm{t}$, respectively, $\mathrm{k}_{1}\left(\mathrm{~min}^{-1}\right)$ is the pseudo-first-order rate constant and $\mathrm{k}_{2}\left(\mathrm{~g} \mathrm{mg}^{-1}\right.$ $\min ^{-1}$ ) is the pseudo-second-order rate constant. $k_{1}$ is calculated by plotting $\log \left(q_{e}-q_{t}\right)$ vs $t$ and $k_{2}$ is calculated by plotting $t / q_{t}$ vs $t$. The characteristic parameters of the studied kinetic models and their corresponding correlation coefficients are presented in Table 1. It can be observed that $\mathrm{CR}$ dye can be well described by the pseudo-first-order adsorption mechanism. For MO dye, the second-order model has higher correlation coefficients $\left(R^{2} \approx 0.99\right)$ compared to the correlation coefficients of pseudo-first-order for both (NVP/RS) and (AAm/RS) composite hydrogels. Obviously, the adsorption of MO onto (NVP/RS) and (AAm/RS) can be well described by the pseudosecond-order adsorption mechanism and adsorption 

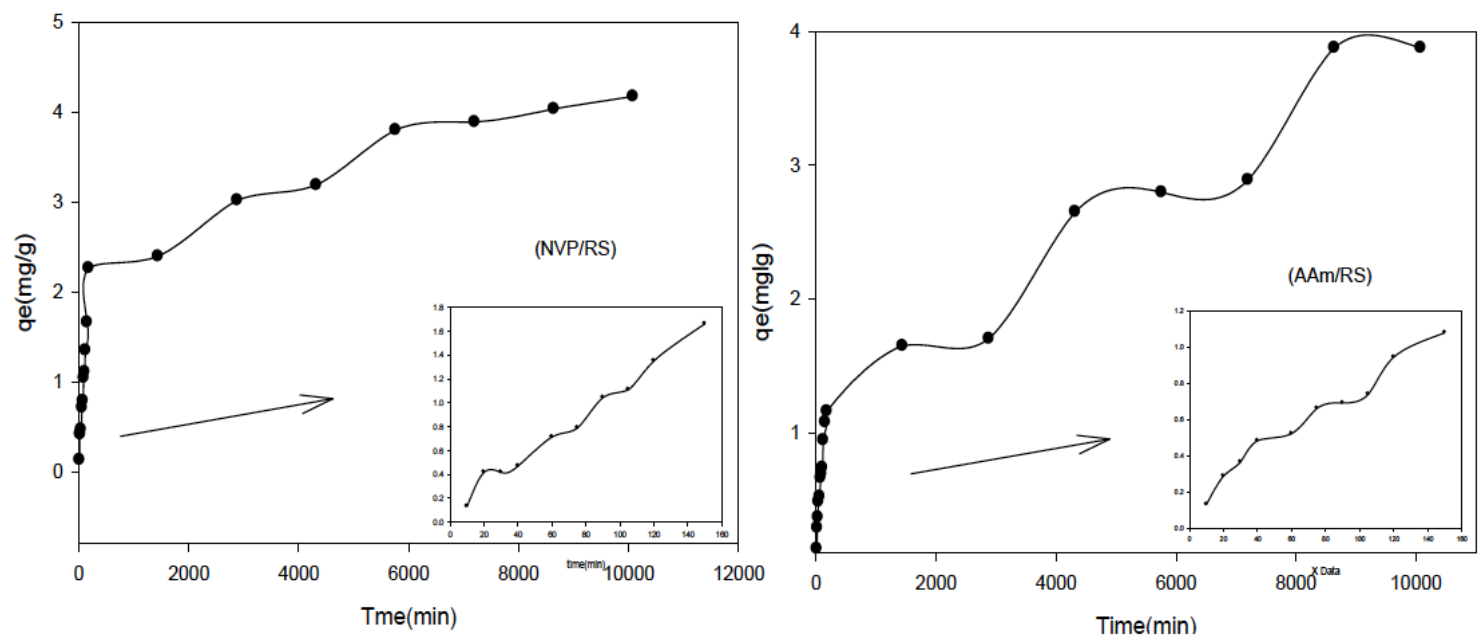

(a)
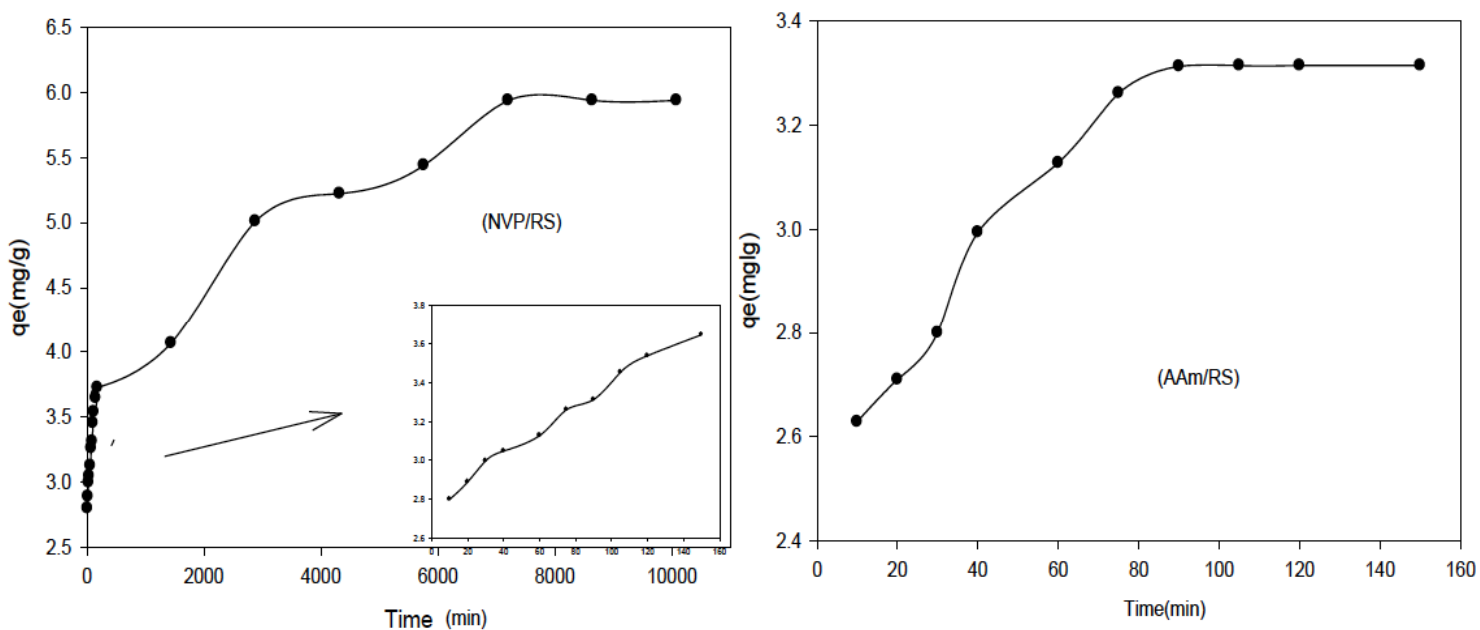

(b)

Figure 9: Effect of contact time on the adsorption of $\mathrm{CR}(\mathbf{a})$ and $\mathrm{MO}(\mathbf{b})$ by (NVP/RS) and (AAm/RS) composite hydrogels at $\mathrm{pH}$; 7 , temperature; $25^{\circ} \mathrm{C}$ and initial dye concentration; $10 \mathrm{mg} / \mathrm{L}$.

Table 1: Pseudo First Order and Pseudo Second Order Parameters for Adsorption of CR and MO Dyes onto (NVP/RS) and (AAm/RS) Composite Hydrogels

\begin{tabular}{|c|c|c|c|c|c|}
\hline \multirow[t]{2}{*}{ Model } & \multirow[t]{2}{*}{ Parameters } & \multicolumn{2}{|c|}{ (NVP/RS) } & \multicolumn{2}{|c|}{ (AAm/RS) } \\
\hline & & CR & MO & CR & MO \\
\hline & $\mathrm{q}_{\mathrm{e}, \exp }(\mathrm{mg} / \mathrm{g})$ & 3.9 & 5.9 & 2.8 & 3.3 \\
\hline \multirow[t]{3}{*}{ Pseudo-first order } & $\mathrm{k}_{1}\left(\min ^{-1}\right) \times 10^{-3}$ & 3.5 & 8.12 & 2.7 & 2.2 \\
\hline & $\mathrm{q}_{\mathrm{e}, \mathrm{cal}}(\mathrm{mg} / \mathrm{g})$ & 3.8 & 1.4 & 2.75 & 3.1 \\
\hline & $\mathrm{R}^{2}$ & 0.976 & 0.960 & 0.976 & 0.981 \\
\hline \multirow[t]{3}{*}{ Pseudo-second order } & $\mathrm{k}_{2}(\mathrm{~g} / \mathrm{mg} \min )$ & 0.0611 & 0.033 & 0.01 & 0.05 \\
\hline & $\mathrm{q}_{\mathrm{e}, \mathrm{cal}}(\mathrm{mg} / \mathrm{g})$ & 0.98 & 3.8 & 1.29 & 3.5 \\
\hline & $\mathrm{R}^{2}$ & 0.958 & 0.996 & 0.950 & 0.998 \\
\hline
\end{tabular}

rate of $\mathrm{MO}$ onto (NVP/OP) hydrogel is probably controlled by the chemical process [25].

Figure 10 illustrates the effect of the initial dye concentration on the adsorption capacity and the dye removal percent of various investigated composite hydrogels by varying the dye concentrations between 10 to $80 \mathrm{mg} / \mathrm{L}$. It can be observed that the percentage of dye removal decreases with an increase in the initial dye concentration, which may be due to the saturation 
of adsorption sites on the adsorbent surface [26]. At a low concentration there will be unoccupied active sites on the adsorbent surface, and when the initial dye concentration increases, the active sites required for adsorption of the dye molecules will lack [27]. On the other hand the increase in initial dye concentration will cause an increase in the loading capacity of the adsorbent and this may be due to the high driving force for mass transfer at a high initial dye concentration [28]. The adsorption isotherm is important for the description of how the adsorbate will interact with the adsorbent and give an idea of the adsorption capacity of the adsorbent. To discuss the adsorption isotherm, two commonly models are investigated the Langmuir model and the Freundlich model. The Langmuir model [29] represents a monolayer sorption process onto a homogenous surface and can be written as:

$\frac{\mathrm{C}_{\mathrm{e}}}{\mathrm{q}_{\mathrm{e}}}=\frac{\mathrm{C}_{\mathrm{e}}}{\mathrm{q}_{\max }}+\frac{1}{\mathrm{~b} \cdot \mathrm{q}_{\max }}$

where qe is the adsorbed amount at equilibrium $(\mathrm{mg} / \mathrm{g})$, $\mathrm{q}_{\max }$ maximum adsorption capacity $\left(\mathrm{mg} \mathrm{g}^{-1}\right)$, Ce
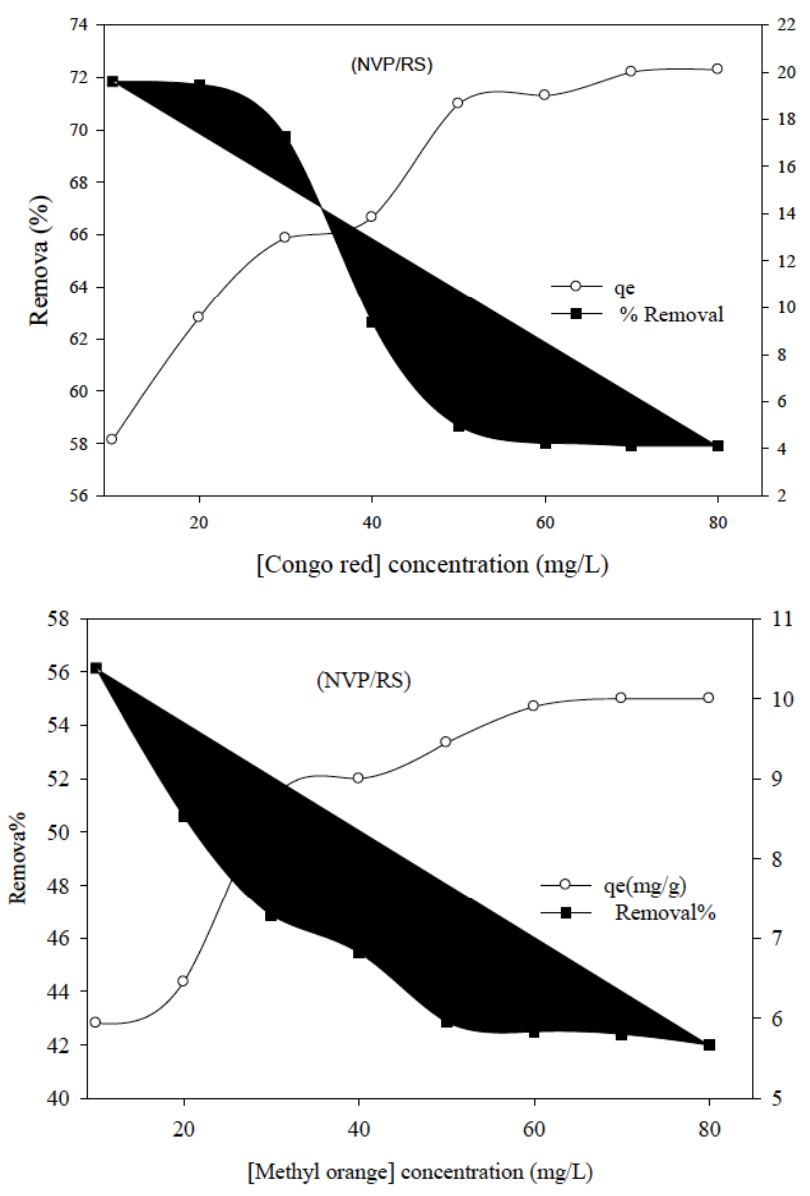

equilibrium dye concentration in solution $\left(\mathrm{mg} \mathrm{L}^{-1}\right)$,b Langmuir constant $\left(\mathrm{L} \mathrm{mg}^{-1}\right)$

The Freundlich model [30] is applied to describe a heterogeneous system characterized by a heterogeneity factor of $1 / \mathrm{n}$. This model describes reversible adsorption and is not restricted to the formation of the monolayer can be written as:-

$\log q_{e}=\log K_{F}+1 / n \log C_{e}$

where $K_{F}$ is the Freundlich constant, $1 / n$ is the heterogeneity factor which is related to the capacity and intensity of the adsorption. The parameters of the two isotherm models are evaluated and summarized in Table 2. The higher values for correlation coefficients $\left(R^{2}\right)$ for both models reveal the applicability of these isotherms on the ongoing adsorption process. But the most appropriate model for the adsorption of $C R$ and MO onto (NVP/RS) hydrogel is the Freundlich model. This means the sorption of CR and MO onto (NVP/RS) hydrogel is heterogeneous energy distribution. The values of $\mathrm{n}$ are more than unit; it means the favorable adsorption intensity for CR and MO onto (NVP/RS). In
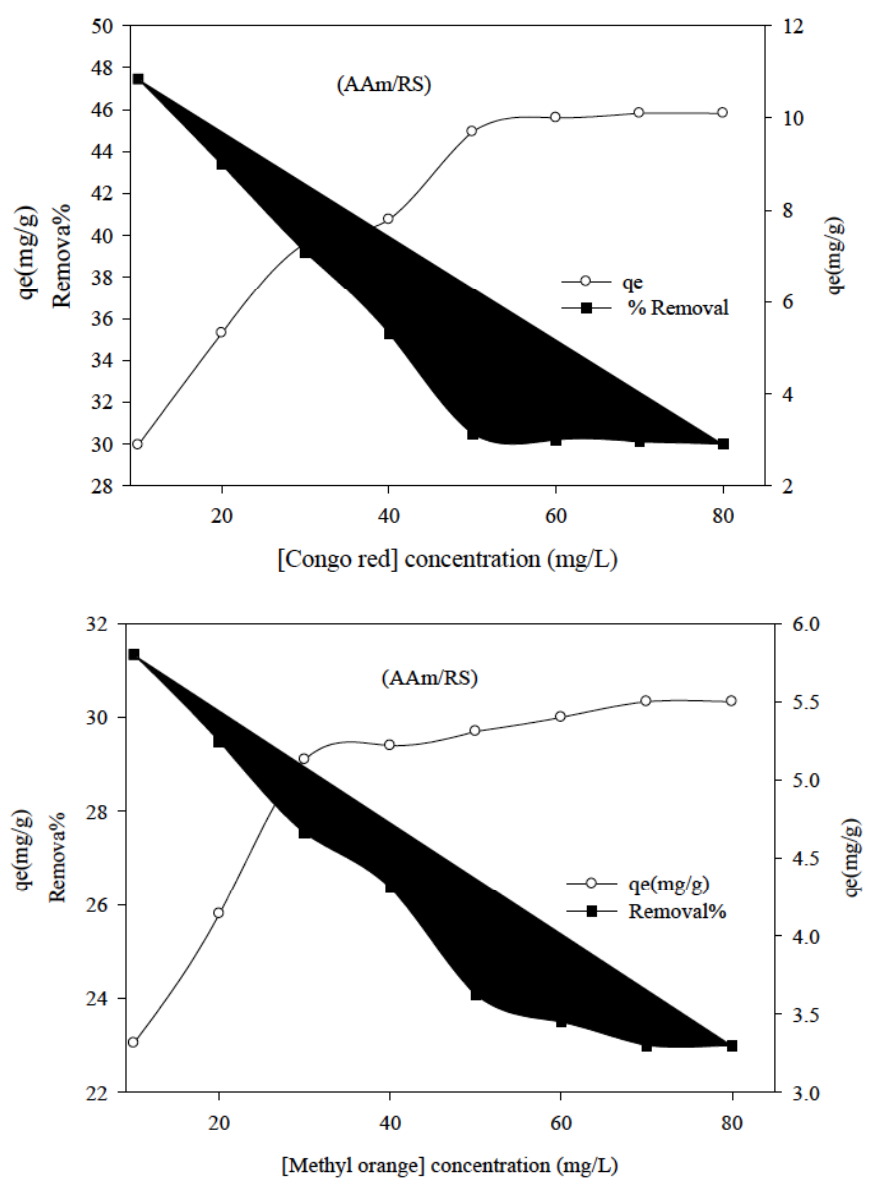

Figure 10: Effect of initial concentration on the adsorption of CR and MO by (NVP/RS) and (AAm/RS) composite hydrogels at contact time $24 \mathrm{~h}, \mathrm{pH} ; 7$ and temperature; $25^{\circ} \mathrm{C}$. 
Table 2: Parametrs of Langmuir and Freundlich Isotherm Models

\begin{tabular}{|c|c|c|c|c|c|}
\hline \multirow[t]{2}{*}{ Model } & \multirow[t]{2}{*}{ Parameters } & \multicolumn{2}{|c|}{ (NVP/RS) } & \multicolumn{2}{|c|}{ (AAm/RS) } \\
\hline & & CR & MO & CR & MO \\
\hline \multirow[t]{3}{*}{ Langmuir } & $\mathrm{q}_{\mathrm{m}}\left(\mathrm{mg}^{-1}\right)$ & 34.24 & 14.5 & 15.8 & 12.59 \\
\hline & $\mathrm{k}_{\mathrm{a}}\left(\mathrm{Lmg}^{-1}\right)$ & 0.0602 & 0.0330 & 0.0472 & 0.099 \\
\hline & $\mathrm{R}^{2}$ & 0.9749 & 0.9800 & 0.9972 & 0.9990 \\
\hline \multirow[t]{4}{*}{ Freundlich } & $K_{\mathrm{F}}\left(\mathrm{mg} \mathrm{g}(\mathrm{L} / \mathrm{g})^{-1 / \mathrm{n}}\right)$ & 2.53 & 2.3 & 1.14 & 0.67 \\
\hline & $1 / n$ & 0.675 & 0.47 & 0.6219 & 0.66 \\
\hline & $\mathrm{n}$ & 1.45 & 2.09 & 1.6079 & 1.5082 \\
\hline & $\mathrm{R}^{2}$ & 0.9800 & 0.9940 & 0.9870 & 0.9900 \\
\hline
\end{tabular}

case of adsorption of $\mathrm{CR}$ and $\mathrm{MO}$ onto (AAm/RS) composite hydrogel, $R^{2}$ values of the Langmuir equation are higher than 0.990 for both, indicating that the Langmuir model adequately described the adsorption of $\mathrm{CR}$ and $\mathrm{MO}$ onto (AAm/RS). The surface phase may be considered as a monolayer kinetic is based on the ideal monolayer adsorbed model. The Langmuir isotherm is the most popular isotherm model and it is used to describe the adsorption process where the occupancy occurs at on one adsorption site at an energetically homogeneous range of adsorption sites [31].

The effect of temperature on the adsorption of CR and $\mathrm{MO}$ dyes onto the (NVP/RS) and (AAm/RS) composite hydrogels was investigated at 20, 40 and 60 ${ }^{\circ} \mathrm{C}$ and shown in Table 3 . The results indicate that, when the temperature is increased the adsorption capacity of $\mathrm{CR}$ and $\mathrm{MO}$ dyes onto the investigated hydrogels also increased. This may be due to increasing the mobility of the dye molecules and they have sufficient energy to interact with active site [32]. This means the adsorption of $\mathrm{CR}$ and MO dyes onto both composite hydrogels is endothermic reaction.

The thermodynamic parameters Gibb's free energy $\left(\Delta G^{\circ}\right)$, enthalpy change $\left(\Delta H^{\circ}\right)$ and entropy change $\left(\Delta S^{\circ}\right)$ were calculated using the following equations [33]:

$\ln \mathrm{K}_{\mathrm{D}}=-\frac{\Delta \mathrm{H}}{\mathrm{RT}}+\frac{\Delta \mathrm{S}}{\mathrm{R}}$

$\Delta \mathrm{G}^{\circ}=\Delta \mathrm{H}^{\circ}-\mathrm{T} \Delta \mathrm{S}^{\circ}$

Where $\mathrm{R}$ is the ideal gas constant $(8.314 \mathrm{~J} / \mathrm{mol} \mathrm{K})$, $T$ is the temperature $(K)$, and $K_{D}$ is the distribution coefficient $\left(\mathrm{K}_{\mathrm{D}}=\mathrm{q}_{\mathrm{e}} / \mathrm{C}_{\mathrm{e}}\right)$. The values of $\Delta \mathrm{H} \circ$ and $\Delta \mathrm{S}$ 。 were calculated by plotting of $\ln K_{D}$ against $1 / T$; the slope and the intercept correspond to $\Delta H \circ / R$ and $\triangle S \circ / R$, respectively. $\triangle G^{\circ}(\mathrm{kJ} / \mathrm{mol})$ was calculated from eq(12). The thermodynamic parameters for adsorption of DCR and MO dyes onto the investigated hydrogels were calculated and summarized in Table 4 . It can be observed that the positive values of $\Delta \mathrm{H}^{\circ}$ confirm the endothermic nature of adsorption of both dyes. It is also observed that, the enthalpy change values are lower than $40 \mathrm{~kJ} / \mathrm{mol}$ indicate physisorption adsorption of dyes at the three experimental temperatures means that the adsorption is physical process. Generally, the change in adsorption enthalpy for physisorption is in the range of -20 to $40 \mathrm{~kJ} / \mathrm{mol}$. The endothermic CR and $\mathrm{MO}$ adsorption onto other adsorbent systems have also been reported. It can be also observed that the negative values of $\Delta \mathrm{G} \circ$ in adsorption of $\mathrm{CR}$ over different hydrogel imply the spontaneous nature of the adsorption process. Further, the decrease in negativity $\Delta G^{\circ}$ values with rising temperature indicates that the adsorption is more spontaneous at higher temperatures [34]. Similar observation is made in the adsorption of $\mathrm{CR}$ by magnetic cellulose/ $\mathrm{Fe}_{3} \mathrm{O}_{4}$ /activated carbon composite [35]. The $\Delta \mathrm{G}$ * values of adsorption of $M O$ onto (NVP/RS) and (AAm/RS) composite hydrogel are positive and decrease with rising temperature. This means higher temperature makes the adsorption easier i.e. the adsorption is more favorable at high temperatures. Similar observation is made in the adsorption of $\mathrm{Cu}$ (II) ions onto dialdehyde amino thiazole starch and decrease in $\Delta G^{\circ}$ with the increase temperature shows that the adsorption is more favorable at high temperatures. The positive values of $\Delta S^{\circ}$ suggests increasing the randomness at the solid solution interface occurs in the internal structure of the sorption of $\mathrm{CR}$ and $\mathrm{MO}$ dye onto hydrogel onto onto the (NVP/RS) and (AAm/RS) composite hydrogels.

\section{Consecutive Adsorption onto the Composite Hydrogels}

The CR adsorbed (NVP/ RS) and (AAm/ RS) composite hydrogels were used to adsorb $\mathrm{MO}$ dye to 
Table 3: Thermodynamic Parameters of CR and MO Dyes onto (NVP/OP) Hydrogel

\begin{tabular}{|c|c|c|c|c|c|c|}
\hline $\begin{array}{l}\frac{0}{0} \\
\frac{0}{E} \\
\text { ஸे }\end{array}$ & $T(K)$ & $q_{e}(\mathrm{mg} / \mathrm{g})$ & $\begin{array}{c}\Delta \mathrm{G}^{\circ} \\
\left(\mathrm{KJmol}^{-1}\right)\end{array}$ & $\begin{array}{c}\Delta S^{\circ} \\
(\mathrm{KJ} \text { mol-1) }\end{array}$ & $\begin{array}{c}\Delta \mathrm{H}^{\circ} \\
\left(\mathrm{KJ} \mathrm{mol}^{-1}\right)\end{array}$ & $\mathbf{R}^{2}$ \\
\hline \multicolumn{7}{|c|}{ CR Dye } \\
\hline \multirow{3}{*}{$\begin{array}{l}\infty \\
\frac{\infty}{\alpha} \\
\sum\end{array}$} & 293 & 4.3 & -1.34135 & \multirow{3}{*}{185.4} & \multirow{3}{*}{52.92692} & \multirow{3}{*}{0.997} \\
\hline & 313 & 5.6 & -5.65693 & & & \\
\hline & 333 & 5.9 & -8.72186 & & & \\
\hline \multirow{3}{*}{ 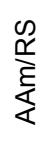 } & 293 & 2.8 & 1.235586 & \multirow{3}{*}{77.3} & \multirow{3}{*}{23.78635} & \multirow{3}{*}{0.998} \\
\hline & 313 & 4.01 & -0.6756 & & & \\
\hline & 333 & 4.5 & -1.82675 & & & \\
\hline \multicolumn{7}{|c|}{ MO Dye } \\
\hline \multirow{3}{*}{$\begin{array}{l}\text { n } \\
\stackrel{\underline{\alpha}}{\alpha} \\
\sum\end{array}$} & 293 & 5.9 & 0.359687 & \multirow{3}{*}{4.8221} & \multirow{3}{*}{1.795824} & \multirow{3}{*}{0.983} \\
\hline & 313 & 6.07 & 0.273407 & & & \\
\hline & 333 & 6.1 & 0.194242 & & & \\
\hline \multirow{3}{*}{ 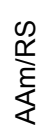 } & 293 & 3.3 & 2.8982 & \multirow{3}{*}{7.4826} & \multirow{3}{*}{5.11311} & \multirow{3}{*}{0.981} \\
\hline & 313 & 3.5 & 2.824431 & & & \\
\hline & 333 & 3.9 & 2.592231 & & & \\
\hline
\end{tabular}

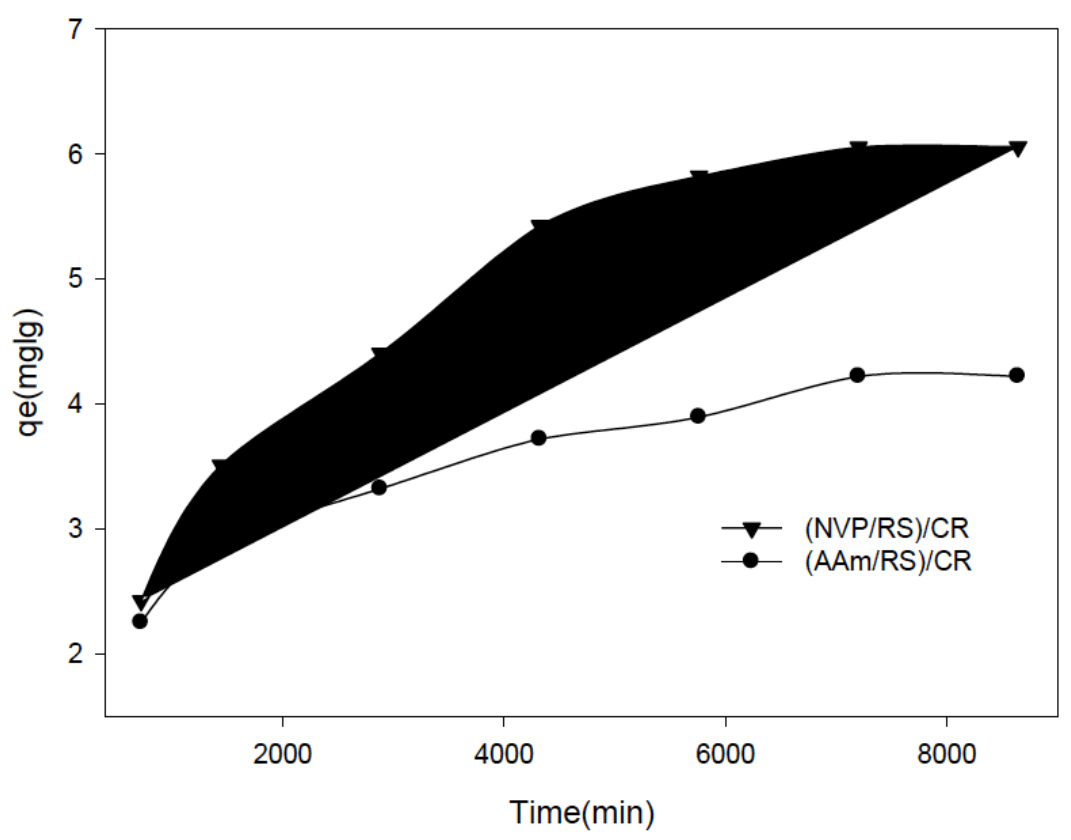

Figure 11: Effect of contact time on the adsorption MO of $10 \mathrm{mg} / \mathrm{L}$ by (NVP/RS) and (AAm/RS) composite hydrogels loaded with $\mathrm{CR}$ at $\mathrm{pH} ; 7$ and temperature; $25^{\circ} \mathrm{C}$.

know the applicability of hydrogels for consecutive adsorption. In the previous part we were found that MO has less ability for adsorption onto (NVP/RS) and (AAm/RS) composite hydrogel. So, we were chosen $\mathrm{MO}$ for the second adsorption to study the efficiency of this process. The kinetic study of $\mathrm{MO}$ adsorption onto (NVP/ RS)/CR and (AAm/ RS)/CR are performed at $\mathrm{pH}=7$ to avoid desorption of dye and shown in Figure
11. It can be observed that, as the contact time is increased the dye adsorption also increased until reached the equilibrium. Good results are obtained in the second adsorption compared with the first one (Figure 9). It may be due to the surfaces of (NVP/RS)/CR and (AAm/RS)/CR was covered with a layer of dyes, which increase the electrostatic attraction between adsorbent and MO molecules. 


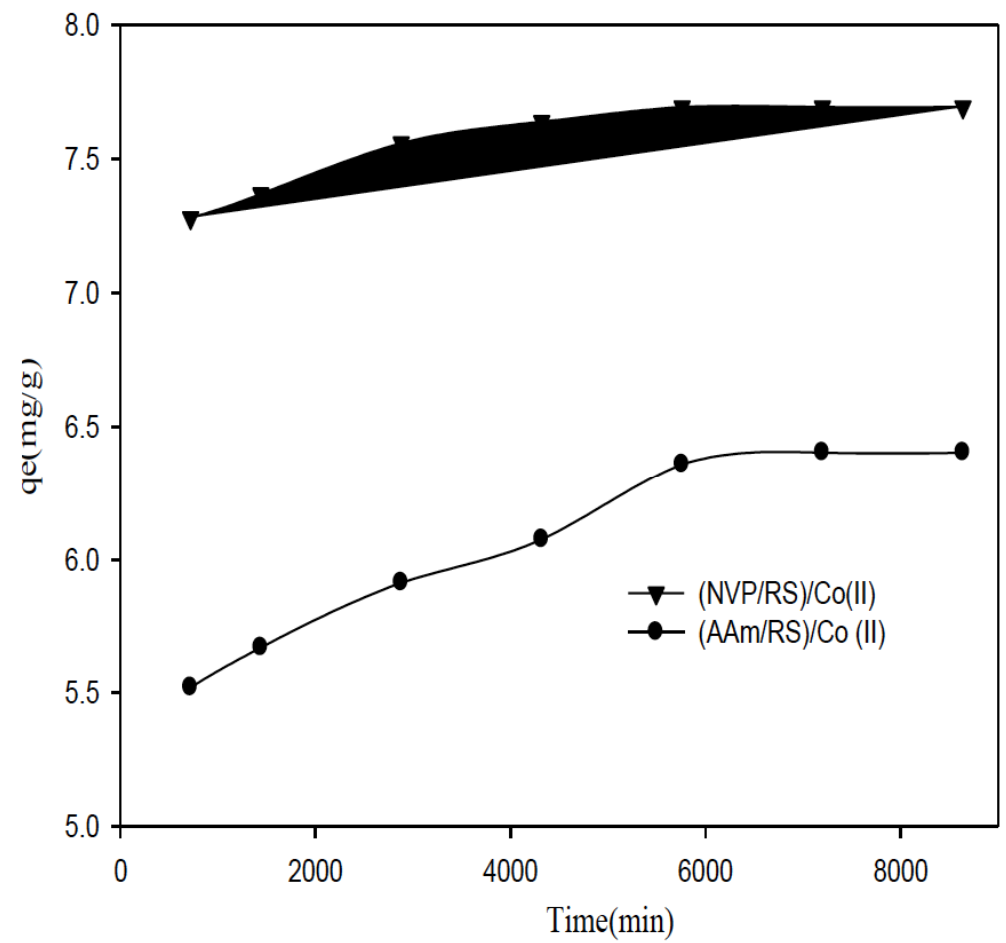

Figure 12: Effect of contact time on the adsorption $\mathrm{MO}$ of $10 \mathrm{mg} / \mathrm{L}$ by (NVP/RS) and (AAm/RS) composite hydrogels loaded with Co (II) of $10 \mathrm{mg} / \mathrm{L}$ at $\mathrm{pH} ; 7$ and temperature; $25^{\circ} \mathrm{C}$.

Table 4: Pseudo- Second-Order Parameters for Second Adsorption of MO Dye

\begin{tabular}{|c|c|c|c|c|}
\hline Parameters & (NVP/ RS)/CR & (AAm/ RS)/CR & (NVP/ RS)/Co & $\mathrm{AAm} / \mathrm{RS}$ )/Co \\
\hline$q_{\exp }(m g / g)$ & 6.03 & 4.20 & 7.76 & 6.50 \\
\hline $\mathrm{k}_{2} \times 10^{-4}(\mathrm{~g} / \mathrm{mg} \mathrm{min})$ & 0.85 & 3.00 & 0.21 & 0.67 \\
\hline $\mathrm{q}_{\mathrm{e}}, \mathrm{cal}(\mathrm{mg} / \mathrm{g})$ & 7.30 & 4.30 & 7.80 & 6.50 \\
\hline $\mathrm{R}^{2}$ & 0.9910 & 0.9980 & 0.9900 & 0.9990 \\
\hline
\end{tabular}

In most cases the wastewater contains heavy metal ions with dyes. Whatever, it was be studied the adsorption of $\mathrm{MO}$ as a second adsorption onto (NVP/ $\mathrm{RS}$ ) and (AM/ RS) loaded with $10 \mathrm{mg} / \mathrm{L}$ of $\mathrm{Co}(\mathrm{II})$ ions and the results are shown in Figure 12. It can be noted that, the $\mathrm{MO}$ adsorption increases with time until reached the equilibrium. Improvement in the MO adsorption onto (NVP/RS) and (AAm/ RS)/ loaded $\mathrm{Co}(\mathrm{II})$. The maximum adsorption of (NVP/ RS) composite hydrogel towards MO was $6.21 \mathrm{mg} / \mathrm{g}$ which becomes $7.76 \mathrm{mg} / \mathrm{g}$ for (NVP/ RS)/Co(II) composite hydrogel. For (AAm/ RS) composite hydrogel the maximum adsorption towards $\mathrm{MO}$ was $3.35 \mathrm{mg} / \mathrm{g}$ which becomes $6.50 \mathrm{mg} / \mathrm{g}$ for (AAm/ RS)/Co(II) composite hydrogel. This means increasing the adsorption capacity of both (NVP/RS) and (AAm/ RS) composite hydrogels towards $\mathrm{MO}$ dye by 24.7987 and 91.3433 , respectively. This may be due to formation of complex between cobalt ion and dye MO. The kinetic behavior of the second dye adsorption process was analyzed using the pseudo-second-order and the data are summarized in Table 4. It can be observed that, the adsorption of MO onto the (NVP/ RS) and (AAm/ RS) composite hydrogels loaded with $\mathrm{CR}$ or $\mathrm{Co}$ (II) can be well described by the pseudo-second-order adsorption mechanism and the adsorption rates were probably controlled by the chemical process. The pseudosecond-order model is based on the assumption that the rate-determining step may be a chemical sorption involving valence forces through sharing of electrons between adsorbent and adsorbate [36].

\section{CONCLUSIONS}

In this study the composite hydrogels of rice straw and $\mathrm{N}$-vinyl-2-pyrrolidone or acrylamide were prepared 
using gamma irradiation and used as adsorbent for removal congo red and methyl orange dyes. The most important conclusions of this investigation are the following:

- The maximum removal of $\mathrm{CR}$ and $\mathrm{MO}$ onto $(\mathrm{AAm} / \mathrm{RS})$ and $(\mathrm{NVP} / \mathrm{RS})$ was done at $\mathrm{pH}=7$.

- $\quad$ The adsorption capacity of (NVP/RS) composite hydrogel towards the investigated dyes is higher than $(\mathrm{AAm} / \mathrm{RS})$ one.

- The adsorption of MO onto (NVP/RS) and (AAm/RS) was described well by the pseudosecond-order adsorption mechanism while the pseudo-first-order was fitted well the adsorption of CR onto both composite hydrogels.

- The adsorption isotherm was closely fitted with the Freundlich model for adsorption of $\mathrm{CR}$ and MO onto (NVP/RS) and the Langmuir model for adsorption dyes onto (AAm/RS).

- $\quad \Delta \mathrm{H}^{\circ}$ values were positive values confirmed the endothermic nature of adsorption of both dyes.

- Good results were obtained in the second adsorption of $\mathrm{MO}$ onto the composite hydrogels loaded with $\mathrm{CR}$ dye

- Improvement in the MO adsorption onto (NVP/RS) and (AAm/ RS)/ loaded Co(II).

\section{REFERENCES}

[1] El-Hag Ali A, Raafat Al,Mahmoud GA, Badway NA, ElMottaleb MA, Elshahawy. J Inorg Organomet Polym 2016; 26 (3): 606-615.

[2] Tan IAW, Hameed BH, Ahmad AL. Chem Eng J 2007; 127: 111-119. https://doi.org/10.1016/j.cej.2006.09.010

[3] Yao Z, Wang L, Qi J. Clean (Weinh) 2009; 37 (8): 642-648.

[4] Zhu HY, Fua YQ, Jiang R, Jiang J-H, Xia Z G-M, Zhao S-L, Wang Y. Chem Eng J 2011; 173: 494-502. https://doi.org/10.1016/j.cej.2011.08.020

[5] Mahmoud GA, Samia EA, Badway NA, Abo Farha SA, Alshafei EA. Starch/Stärke 2013; 65: 1-10. https://doi.org/10.1002/star.201200143

[6] Dalaran $M$, Emik S, Güçlü G, lyim TB, Özgümüş S. Desalination 2011; 279: 170-182.

https://doi.org/10.1016/j.desal.2011.06.004

[7] Vishakha k, Kishor B, Sudha R. Int J Res Pharm Biomed Sci 2012; 3: 1597-1613.

[8] Albadarin AB, Collins MN, Naushad M, Shirazian S, Walker G, C. Mangwandi, Chem Eng J 2017; 307: 264-272. https://doi.org/10.1016/j.cej.2016.08.089
[9] Liang S, Guo XY, Feng NC, Tian QH. J Hazard Mater 2009; 174(1-3): 756-762.

https://doi.org/10.1016/j.jhazmat.2009.09.116

[10] Zhang WX, Li HJ, Yan H, Jiang ZW, Kan XW, Dong L, Yang H, Li AM, Cheng R. Bioresource Tech 2012; 117: 40-47. https://doi.org/10.1016/..biortech.2012.04.064

[11] Singh B, Kumar S. Nucl. Instr. Meth. Phys. Res 2008; 266: 3417-3430.

https://doi.org/10.1016/j.nimb.2008.04.022

[12] Mahmoud GA, Abdel-Aal SE, Badway NA, Elbayaa AA, Ahmed DF. Polym Bull (2016); DOI 10.1007/s00289-0161717-0.

[13] Karadag E, Saraydin D, Sahiner N, Guven O. J Macromol. Sci.-Pure Appl Chem A 2001; 38 (11):1105-1114.

[14] Qudah YH, Raafat Al, El-Hag AA. Arab J Nucl Sci Appl 2013; 46: 80-91.

[15] Chakraborty S, Chowdhury S, Saha PD. Carbohydr Polym 2011; 86: 1533-1541. https://doi.org/10.1016/j.carbpol.2011.06.058

[16] Zhang $\mathrm{Y}$, Chi $\mathrm{H}$, Zhang $\mathrm{W}$, Sun $\mathrm{Y}$, Liang $\mathrm{Q}, \mathrm{Gu} \mathrm{Y}$, Jing $\mathrm{R}$. Nano-Micro Lett 2014; 6(1): 80-87. https://doi.org/10.1007/BF03353772

[17] Kang W, Wang A. J Polym Res 2013; 20: 110-117. https://doi.org/10.1007/s10965-012-0070-8

[18] Panda GC, Das SK, Guha AK. J Hazard Mater 2009; 164 374-379. https://doi.org/10.1016/j.jhazmat.2008.08.015

[19] Mohammadi N, Khani H, Amereh E, Agarwal S. J Colloid Interf Sci 2011; 362: 457-462. https://doi.org/10.1016/j.jcis.2011.06.067

[20] Deshmukh SR, Singh RP. J Appl Poly Sci 1987; 33: 19631975. https://doi.org/10.1002/app.1987.070330610

[21] Bratby J. Coagulation and Flocculation Uplands Press Ltd; 1980.

[22] Cheah W, Hosseini S, Khan MA, Chuah TG, Choong, TSY. Chem Eng J 2013; 215-216: 747-754.

https://doi.org/10.1016/j.cej.2012.07.004

[23] Lagergren, S. Kungliga Svenska Vetenskapsakademiens Handlingar 1898; 24: 1-39

[24] Ho S, Water Res 2006; 40: 119-125. https://doi.org/10.1016/j.watres.2005.10.040

[25] Mahmoud GA, Mohamed SF. Aust J Basic Appl Sci 2012; 6(6): 262-272.

[26] Eren Z, Acar FN. Desalination 2006; 194: 1-10. https://doi.org/10.1016/j.desal.2005.10.022

[27] Kannan N, Sundaram MM. J Dyes Pig 2001; 51:25-40. https://doi.org/10.1016/S0143-7208(01)00056-0

[28] Bulut Y, Aydin H. Desalination 2006; 194: 259-267. https://doi.org/10.1016/j.desal.2005.10.032

[29] Langmuir I. J Amer. Chem. Soc. 1916; 38: 2221-2295. https://doi.org/10.1021/ja02268a002

[30] Freundlich HMF. Phy Chem J1906; 57: 385-471.

[31] Rudzinski W, Plazinski W. Appl Surf Sci 2007; 253: 5827 5840 .

https://doi.org/10.1016/j.apsusc.2006.12.038

[32] Senthilkumaar S, Kalaamani V, Subburaam PC. J Hazard Mater 2006; 136: 800-808. https://doi.org/10.1016/j.jhazmat.2006.01.045

[33] Boudiaf HZ, Boutahala M, Arab L. Chem Eng J 2012; 187 : 142-149. https://doi.org/10.1016/j.cej.2012.01.112

[34] Mane VS, Babu PV. J Taiwan Inst Chem Eng 2013; 44: 8190. 
[35] Feng YQ, Ju B, Zhang S, Wang X, Yang I. Carbohydr Polym 2008; 72: 326-333. https://doi.org/10.1016/j.carbpol.2007.08.019
[36] Ho, Y-S. Water Res 2006; 40: 119-125.

https://doi.org/10.1016/j.watres.2005.10.040

Received on 20-10-2016

Accepted on 22-02-2017

Published on 04-10-2017

DOI: https://doi.org/10.6000/1929-5995.2017.06.03.4 